\title{
DEFINIÇÃO DAS UNIDADES FISIOGRÁFICAS DO MUNICÍPIO DE SÃO FRANCISCO DE ASSIS, COM APLICAÇÕES DE SIG
}

\author{
DEFINITION OF PHYSIOGRAPHIC UNITS IN THE SÃO FRANCISCO DE ASSIS MUNICIPALITY WITH GIS APPLICATIONS
}

\section{RESUMO}

A compartimentação fisiográfica tem como base os elementos do ambiente que definem a composição das encostas (litologia e solos) e a forma (relevo). Neste trabalho, utilizou-se os elementos do ambiente combinados com Sistemas de Informações Geográficas e árvores de decisão no intuito de descrever, classificar e compartimentar o município de São Francisco de Assis, localizado na Bacia do rio Ibicuí, na porção Oeste do Estado do Rio Grande do Sul. Foram definidos oito unidade fisiográficas, sendo que seis delas são constituídas por subunidades: Unidade Beluno, composta por duas subunidades representa $14,7 \%$ do total da área do município apresenta o relevo mais movimentado do município; Unidade do Chapadão, composta por duas subunidades, ocupa 3,67\%, formado por relevo suave entre escarpas; Unidade Vales Fluviais com 10,32\% da área, ocorre como rampas junto aos rios Ibicuí e Jaguari. Unidade Cerros representa o recuo do Planalto, por ação erosiva e ocorre em 1,51\% da área, com duas subunidades; Unidade Santa Rosa marca as áreas de nascentes da bacia do rio Itu, com área de 6,95\%; Unidade São Francisco de Assis, com 50,23\% da área, é composta por quatro subunidades, constituindo um relevo suave de colinas, com substrato é de rochas sedimentares areníticas e solos arenosos, por vezes gerando campos de areia; Unidade Serra dos Canários, com $5,77 \%$ da área, é composta por duas subunidades, formando as áreas nas maiores altitudes do município; Unidade Vila Kramer, com $6,84 \%$ da área, formando solos, bem desenvolvidos com presença de argila devido a alteração das porções de topo com material vítreo dos derrames. 0 trabalho de compartimentação permite compreender os processos superficias atuantes e auxilia em trabalhos de planejamento.

Palavras-chave: fisiográfico; compartimentação; São Francisco de Assis, morfolitológico; unidades de relevo

\section{ABSTRACT}

The physiographic compartmentalization is based on the elements of the environment that define the composition of the slopes (lithology and soils) and the shape (landforms). In this work, we used the elements of the environment combined with Geographic Information Systems and decision trees. The objective is to describe, classify and compartmentalize the municipality of São Francisco de Assis, located in the Southern Region of Brazil, in the western portion of the State of Rio Grande do Sul. It was determined eight physiographic units and six subunits: Unit Beluno, composed of two subunits represents $14.7 \%$ of the total area, presents the busiest relief of the municipality; Chapadão unit, composed of two subunits, occupies $3.67 \%$, formed by smooth relief between cliffs; Fluvial Valleys Unit with $10.32 \%$ of the area, occurs as ramps along the rivers Ibicui and Jaguari; Cerros Unit represents the Plateau retreat, by erosive action and occurs in $1.51 \%$ of the area, with two subunits; Santa Rosa Unit marks the areas of springs in the Itu river basin, with an area of 6.95\%; São Francisco de Assis Unit, with $50.23 \%$ of the area, is composed of four subunits, constituting a gentle relief of hills, with substrate is sandstone sedimentary rocks and sandy soils, sometimes generating sand fields; Serra dos Canários unit, with $5.77 \%$ of the area, is composed of two subunits, forming the areas at the highest altitudes of the municipality; Vila Kramer Unit, with $6.84 \%$ of the area, forming well developed soils with presence of clay due to alteration of the top portions with vitreous material of the volcanic spills. The work of compartmentalisation allows to understand the superficial processes and helps in planning works.

Keywords: physiographic; compartmentalization; São Francisco de Assis; morphological; relief units

\author{
Luís Eduardo de Souza \\ Robaina ${ }^{\text {a }}$ \\ Romario Trentin ${ }^{\text {a }}$ \\ a Universidade Federal de Santa Maria \\ (UFSM), Santa Maria, RS, Brasil
}

DOI: 10.12957/geouerj.2020.33549

Correpondência: romario.trentin@gmail.com

Recebido em: 10 mar. 2018

Revisado em: 12 out. 2020

Aceito em: 14 out.2020 


\section{INTRODUÇÃO}

O estudo e reconhecimento dos sistemas fisiográficos de um determinado território, com indicação das possíveis fragilidades ambientais, pode auxiliar no planejamento e manejo eficiente do uso do espaço. De acordo com Antonelli e Thomaz (2007), a combinação de diversos dados morfométricos, permite a diferenciação de áreas homogêneas. Estes parâmetros podem revelar indicadores físicos específicos para um determinado local, de forma a qualificarem as informações sobre alterações ambientais.

A compartimentação fisiográfica, através de cruzamentos em SIG, tem como base os "Iandforms" Lollo (1996), entendidos como os elementos do meio que possuem composição (litologia e solos) e uma forma (relevo) com variações das características visuais e físicas. As formas de relevo, as litologias e os solos constituem o substrato físico sobre o qual se desenvolvem as atividades humanas e dessa forma, trabalhos de zoneamentos que determinam unidades homogêneas são fundamentais para entendimento dos processos geomorfológicos e como as ações humanas podem interferir no ambiente.

Teramoto et al. (2001) avaliaram a relação solo, superfície geomórfica e substrato geológico, fazendo interrelações por meio de tabulação cruzada com base no conceito de homogeneidade das superfícies geomorfológicas em relação às unidades de mapeamento de solos e litologia. Esses autores mencionam a relação encontrada entre substrato geológico e unidades de solos, com relação os atributos químicos e físicos dos solos, enquanto os atributos morfológicos dos solos são determinados principalmente pelo relevo.

Procedimentos cartográficos que antes eram realizados de forma manual e sem uma perfeição escalar específica, passam a ser detalhados pelos SIG em um processo extremamente ágil e confiável, permitindo que o pesquisador tenha mais autonomia e precisão no processo cartográfico se suas áreas de estudo. A manipulação de dados de origem espacial toleradas pelos SIG permite ter sobreposição de planos de informação (PI) em uma mesma escala, trazendo precisão a este processo e mais agilidade ao pesquisador (SENA-SOUZA et al 2015).

Neste trabalho, utilizou-se parâmetros de relevo, atributos litológicos e de solos combinados com Sistemas de Informações Geográficas e árvores de decisão no intuito de descrever, classificar e compartimentar o município de São Francisco de Assis, localizado na Região Sul do Brasil, na porção Oeste do Estado do Rio Grande do Sul. A área do município é de 2.501,2 km², estando limitado geograficamente pelas

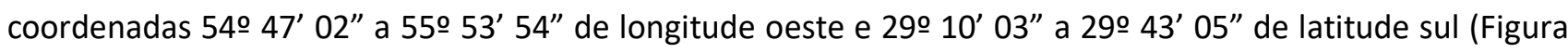
1). 
Figura 1. Mapa de localização do município de São Francisco de Assis

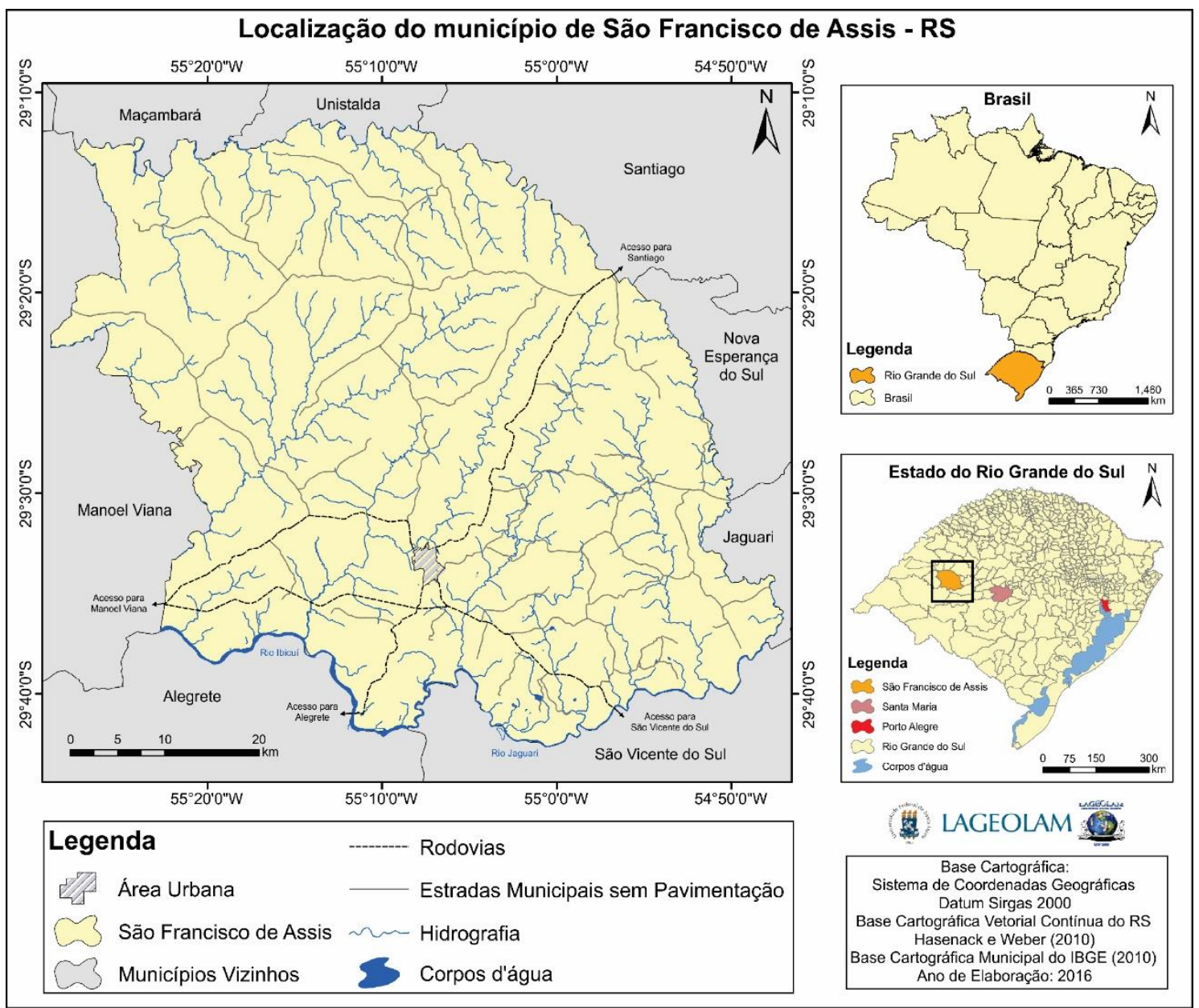

Fonte: Os autores

Seguindo a proposta de compartimentação do estado que foi realizado pelo Projeto RADAMBRASIL incorporado pelo IBGE, em 1986, o município pertence ao Planalto das Missões ao norte e, no restante da área na Depressão Central Gaúcha seguindo, o canal fluvial do rio Ibicuí. Mais recentemente usando esta base de dados o trabalho de compartimentação geomorfológica da bacia hidrográfica do Ibicuí, desenvolvido por Robaina et al (2010) determina que o muncipio de SFA na sua porção Norte está no Planalto das Missões, representado pelos modelados de Patamares das Missões e de Rebordo do Planalto e sua porção Centro-Sul na Depressão Periférica, mais especificamente na Depressão do Ibicuí, nos modelados de Patamares Residuais em Arenitos, Relevo Ondulado em Rochas Friáveis e de Áreas Planas Aluviais.

No trabalho desenvolvido por Robaina et al (2016) foram determinados os compartimentos de relevo para o estado do Rio Grande do Sul, através do uso dos elementos de geomorphons (micro-estruturas fundamentais do relevo) em classificação topográfica automatizada. O município de SFA está representado por elemento flat em uma poção NE e junto aos vales, uma faixa de relevo movimentado marcado por elementos de slope, valley e ridges e, na maior parte do município, predominando elementos de slope e footslope associados a valleye shouder. 
Além desses, a área vem sendo alvo de pesquisas e trabalhos científicos de mapeamento temático da paisagem, como de Menezes et al. (2013), Robaina et al (2015), Suertegaray (1995), Suertegaray et al. (2001), Trentin et al. (2012; 2013, 2015), Trentin \& Robaina (2012) e Verdum (1997, 2004).

\section{METODOLOGIA}

Para a definição das unidades fisiográficas do município de São Francisco de Assis, utilizou-se o auxílio do processamento dos dados e das ferramentas de análise estatística e espacial do SIG Arcgis $10.2^{\circledR}$. Através da organização das bases cartográficas e dos cruzamentos espaciais, foi possível a determinação das unidades e suas referidas subunidades.

Como bases cartográficas, utilizou-se o Modelo Digital de Elevação (MDE) do SRTM, o mapeamento de solos do Estado do Rio Grande do Sul (STRECK et al., 2008), o mapeamento geológico do estado do Rio Grande do Sul (WILDNER et al., 2006) e o zoneamento morfolitológico da bacia hidrográfica do rio Ibicuí (ROBAINA, et al. 2015). O MDE, referente aos dados de Radar do projeto SRTM versão 4.1, com resolução espacial de 3 arco segundos (aproximadamente 90 metros) disponibilizados pelo Serviço Geológico Americano (U.S. GEOLOGICAL SURVEY, 2016). A escolha por esta base de dados ocorreu pela melhor resposta aos processos de validação do MDE, frente à outras bases de dados que, apesar de apresentarem melhor resolução espacial, apresentam diversos tipos de ruídos nos dados, o que condiciona incoerências nos resultados obtidos.

As análises dos dados altimétricos com representação de classes hipsométricas, relacionadas com os dados de inclinação das vertentes e o comprimento das vertentes, possibilitou a definição da classificação das unidades de relevo do município de São Francisco de Assis. Estas unidades de relevo, cruzadas aos dados do substrato geológicos do município permitiu a definição das unidades morfolitológicas, que serviram como camada base para a definição das unidades fisiográficas.

Os dados geológicos do município foram definidos pela adequação cartográfica do mapeamento geológico do estado do Rio Grande do Sul, em escala 1:750.000 (WILDNER et al., 2006). Esta adequação cartográfica foi realizada através de mapeamentos de campo e levantamentos de amostras com análise em laboratório, o que permitiu o ajuste cartográfico à escala compatível com os mapeamentos do município de São Francisco de Assis.

Assim sendo, as unidades morfolitológicas definidas são: as rampas com depósitos recentes, as colinas de arenitos, as colinas de rocha vulcânica, as colinas entre patamares, as colinas de altitudes, as associações de morros e morrotes, os morrotes de arenito e, os morrotes isolados de rocha vulcânica.

A terceira base de dados do cruzamento fisiográfico foi o mapa de solos do município. Este foi realizado com base no mapa de solos do Estado do Rio Grande do Sul, em escala 1:250.000 realizado por (STRECK et al., 2008) tendo seu 
ajuste cartográfico, definido através dos levantamentos e mapeamentos de campo, semelhantes ao mapeamento geológico.

As unidades fisiográficas identificam semelhantes comportamentos frente aos processos superficiais. O mapa de solos é construído na forma de agrupamentos de solos, sendo definidos quatro grandes grupos, sendo eles: solos bem desenvolvidos (correspondendo as ocorrências de Latossolos, Nitossolos e Argissolos do município); os solos mal desenvolvidos (correspondendo às ocorrências de Neossolos litólicos e Cambissolos e as Associações de ambos do município); os solos hidromórficos (correspondendo às ocorrências de Gleissolos e Planossolos do Município) e, os Areais (correspondendo aos campos de areia e associações de campos de areia com Neossolos quartzarênicos).

Os elementos de relevo (geomorphons) que ocorrem no município, que são gerados conforme proposta metodológica de Jasiewicz e Stepinski (2013). Para a realização do processamento do MDE e a geração dos elementos de relevo, utilizou-se a aplicação online, disponibilizada no endereço eletrônico <<http://sil.uc.edu/geom/app >>. 0 código da aplicação também está disponível para baixar em http://sil.uc.edu/. A Figura 2 mostra a espacialização das variáveis utilizadas, mapas base, para a definição das unidades fisiográficas do município de São Francisco de Assis.

A definição das unidades fisiográficas ocorreu através do cruzamento espacial das camadas do mapeamento de solos e do mapeamento das unidades morfolitológicas. Os dados sobre elementos de relevo foram utilizados de forma quali-quantitativas para elaborar a descrição das principais características das unidades obtidas através dos elementos de relevo (geomorphons) presentes no município de São Francisco de Assis.

Após o processamento das informações os trabalhos de campo, percorrendo as principais estradas do município, permitiram a validação do produto cartográfico obtido, sendo registradas informações fotográficas presentes no trabalho e auxiliando nas descrições de informações especificas de cada unidade fisiográfica. Os trabalhos de campo, conforme mencionados anteriormente, são a base para os ajustamentos de escala das bases cartográficas utilizadas, principalmente quanto aos mapeamentos de solos e geologia da área de estudo.

\section{RESULTADOS}

O município de SFA tem suas terras drenadas pela Bacia Hidrográfica do Ibicuí, composta pela seguintes subbacias: BH Itu $\left(594,78 \mathrm{~km}^{2}\right)$, BH Caraguatai $\left(61,52 \mathrm{~km}^{2}\right)$, BH Piraju $\left(29,34 \mathrm{~km}^{2}\right)$, BH Inhacundá $\left(362,47 \mathrm{~km}^{2}\right)$, BH Miracatu $\left(474,24 \mathrm{~km}^{2}\right)$, Sub bacias abaixo de $3^{\circ}$ ordem (Ibicuí) $\left(121,86 \mathrm{~km}^{2}\right), \mathrm{BH}$ Inhanduji $\left(204,06 \mathrm{~km}^{2}\right)$, BH Buricatu $\left(33,11 \mathrm{~km}^{2}\right), \mathrm{BH}$ Piquiri $\left(129,17 \mathrm{~km}^{2}\right)$, BH Jaguari mirim $\left(263,86 \mathrm{~km}^{2}\right)$, BH Sanga Funda $\left(96,12 \mathrm{~km}^{2}\right)$ e Sub bacias abaixo de $3^{\circ}$ ordem (Jaguari) $(138,78)$.

A amplitude altimétrica é de 380 metros, como a menor altitude na cota de 80 metros, junto às planícies do rio Ibícui, e a maior altitude se apresenta na cota de 460 metros, localizada a Nordeste do município. 0 relevo é, 
predominantemente, ondulado com declividades entre 5 a 15\%, formando uma faixa de relevo movimentado de direção NW que separa as terras altas e baixas, caracterizado como rebordo do Planalto.

Figura 2. Mapas base para a definição das unidades fisiográficas do município de São Francisco de Assis

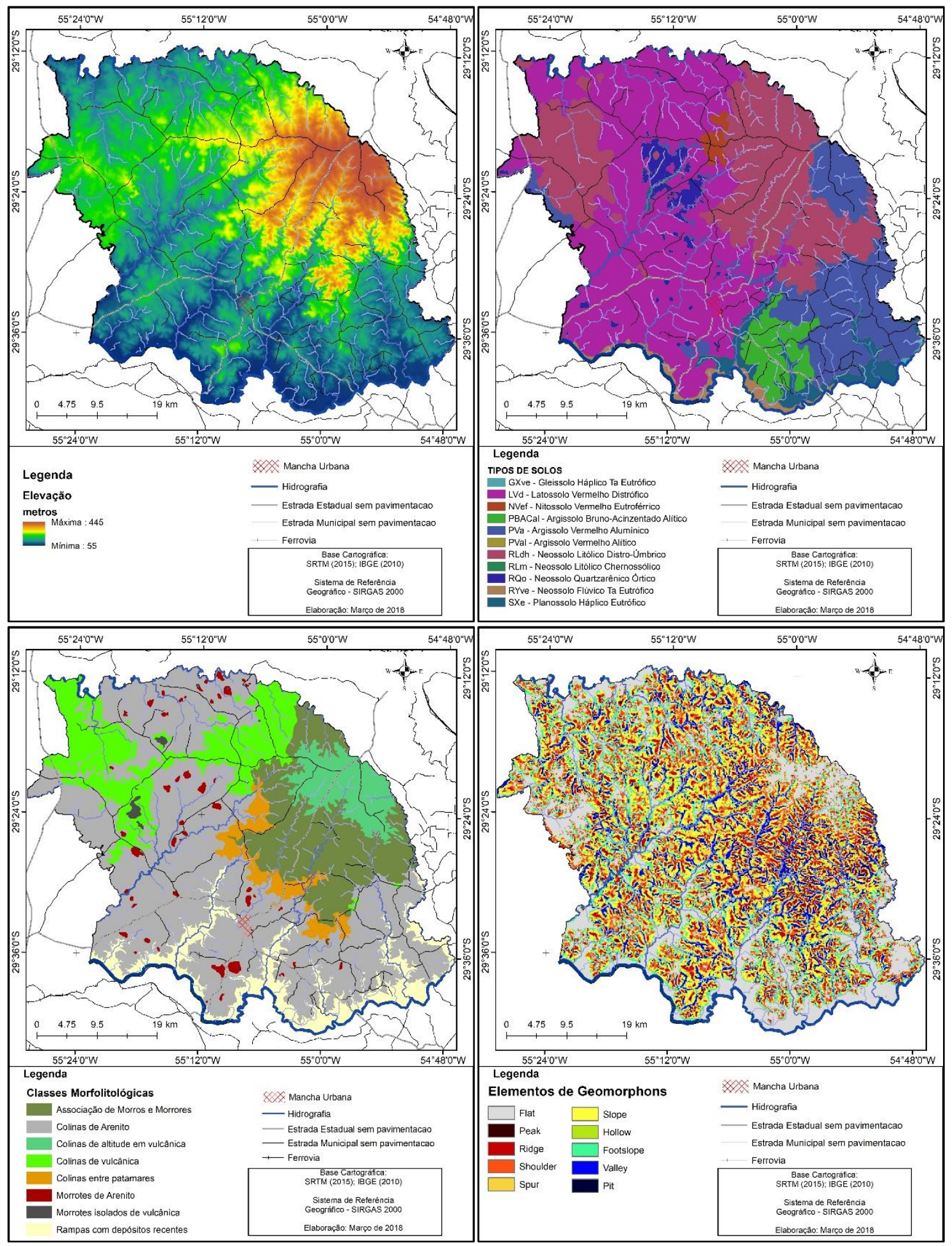

Fonte: Os autores 
As rochas que afloram no município estão associadas a uma sequência vulcano-sedimentar, depositados na Bacia do Paraná. As rochas mais antigas que afloram no município representam as últimas fases de deposição da Bacia do Paraná (Permiano Superior - Triássico) representando o avanço de depósitos continentais e são marcados por uma espessa sucessão flúvio-eólica que corresponde à Formação Sanga do Cabral (Lavina,1988).

No município a sequência fluvial predomina representada por arenitos com presença comum de micas e por apresentar concreções carbonáticas. A outra sequência fluvial, encontrada no município, corresponde a um substrato identificado por uma sequência de arenitos com grânulos e associações com sequência pelíticas de características fluviais que conforme Wildner et al. (2006) constituem a Formação Guará com sedimentação do Período Jurássico. Em algumas porções a alta coesão dos grãos, devido à intensa concentração de óxido de ferro e, por vezes, sílica, confere as rochas maior resistência, geralmente nas camadas superiores, expondo feições de relevo com encostas íngremes e afloramentos de rochas. Por outro lado, estas rochas apresentam-se muito friáveis e, com alto grau de alteração, quando pouco cimentadas, o que condiciona a formação de intensos processos erosivos.

No final do Jurássico, início do Cretáceo com avanço do Deserto na Bacia do Paraná os sedimentos estão representados por uma sequência eólica da Formação Botucatú, compostas por arenito avermelhado, finos a médios, bem selecionados com grãos arredondados e com alta esferecidade.

No Período Cretáceo iniciou-se a gradual fragmentação do grande continente da Pangea gerando pacotes de lavas da Formação Serra Geral de composição básica e ácida. O principal vulcanismo ocorreu na parte média do Cretáceo Inferior (120-130 milhões de anos) tendo, porém, as principais manifestações ocorridas no Jurássico Superior ou mesmo antes Roisenberg e Viero (2002). Estas rochas ocorrem arranjadas conforme um padrão decrescente de idades em direção ao topo. Isso reflete um comportamento de empilhamento de lavas, (provavelmente 5 sequências de derrames), determinados pela observação da textura e estrutura das rochas.

Nos intervalos entre os sucessivos pacotes de lavas ocorre, eventualmente, a deposição de sedimentos arenosos, constituindo os arenitos intertrápicos. As sequências geológicas mais recentes ocorrem nas áreas de acumulação, junto à planície de inundação, na calha dos arroios e ao longo de sua planície de inundação.

Os solos apresentam uma grande variabilidade em função de fatores como o material de origem, relevo e o tempo (estágio de formação em que se encontra), interferindo em características como cor, textura e profundidade, entre outras. Com base em EMBRAPA (1999) no município de São Francisco de Assis encontram-se as seguintes classes de solos (conforme O Sistema Brasileiro de Classificação de Solos - SiBCS - de 1999): solos hidromórficos divididos em Gleissolos, Planossolos e Neossolos quartzarênicos flúvicos; solos mal desenvolvidos do tipo Cambissolos e Neossolos litólicos e quartzarênicos; e os solos bem desenvolvidos que são definidos como Argissolos, Latossolos e Nitossolos. 
Foram definidos para o município de São Francisco de Assis oito unidade fisiográficas, sendo que seis delas são constituidas por subunidades. A figura 3 mostra a espacialização das unidades e subunidades fisiográficas no município e a Tabela 1 apresenta os dados quantitativos das porcentagens de área ocupada pelas unidades e su-unidades.

\section{Unidade Beluno}

A unidade Beluno apresenta o relevo mais movimentado do município (figura 4), marcado pelo recuo da escarpa vulcânica, caracterizada por elementos de valley e ridge estreitas associadas com slope curtos. Esta unidade ocupa 14,7 \% da área total do município. Na subunidade A as rochas são vucânicas e os solos pedregosos mal desenvolvidos. A subunidade B ocorre na passagem do relevo de colinas para de morros e morrotes, onde solos são rasos mas bem desenvolvidos em perfil, formando predominantemente argissolos.

Figura 3. Mapa das unidades fisiográficas do municipio de São Francisco de Assis

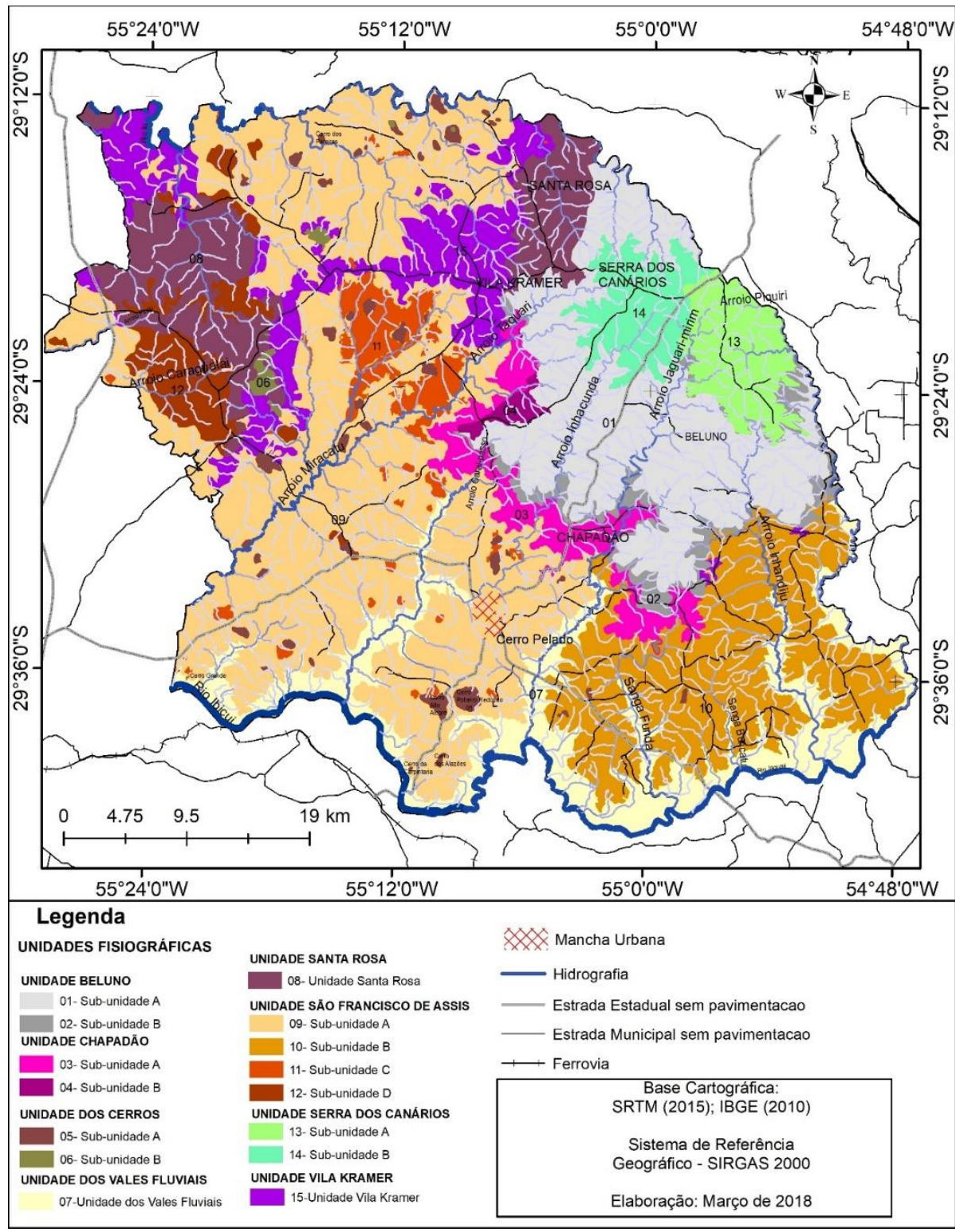

Fonte: Os autores 
Tabela 1. Dados quantitativos das porcentagems de áerea ocupada pelas unidades e subunidades fisiográficas no município de São Francisco de Assis

\begin{tabular}{|c|c|c|c|}
\hline Unidades fisiográficas & Subunidades & $\begin{array}{l}\begin{array}{l}\text { Porcentagem das } \\
\text { subunidades }\end{array} \\
\end{array}$ & $\begin{array}{l}\text { Porcentagem } \\
\text { das unidades }\end{array}$ \\
\hline \multirow{2}{*}{ Unidade Beluno } & Subunidade A & 12,62 & \multirow{2}{*}{14,70} \\
\hline & Subunidade B & 2,08 & \\
\hline \multirow{2}{*}{ Unidade do Chapadão } & Subunidade A & 3,25 & \multirow{2}{*}{3,67} \\
\hline & Subunidade B & 0,43 & \\
\hline \multirow{2}{*}{ Unidade dos Cerros } & Subunidade A & 1,19 & \multirow{2}{*}{1,51} \\
\hline & Subunidade B & 0,32 & \\
\hline Unidade dos Vales Fluviais & Unidade dos Vales Fluviais & 10,32 & 10,32 \\
\hline Unidade Santa Rosa & Unidade Santa Rosa & 6,95 & 6,95 \\
\hline \multirow{4}{*}{ Unidade São Francisco de Assis } & Subunidade A & 32,69 & \multirow{4}{*}{50,23} \\
\hline & Subunidade B & 11,78 & \\
\hline & Subunidade C & 2,86 & \\
\hline & Subunidade D & 2,90 & \\
\hline \multirow{2}{*}{ Unidade Serra dos Canários } & Subunidade A & 3,01 & \multirow{2}{*}{5,77} \\
\hline & Subunidade B & 2,76 & \\
\hline Unidade Vila Kramer & Unidade Vila Kramer & 6,84 & 6,84 \\
\hline
\end{tabular}

Figura 4. Vista do relevo de morros e morrotes da unidade Beluno. 03/2016

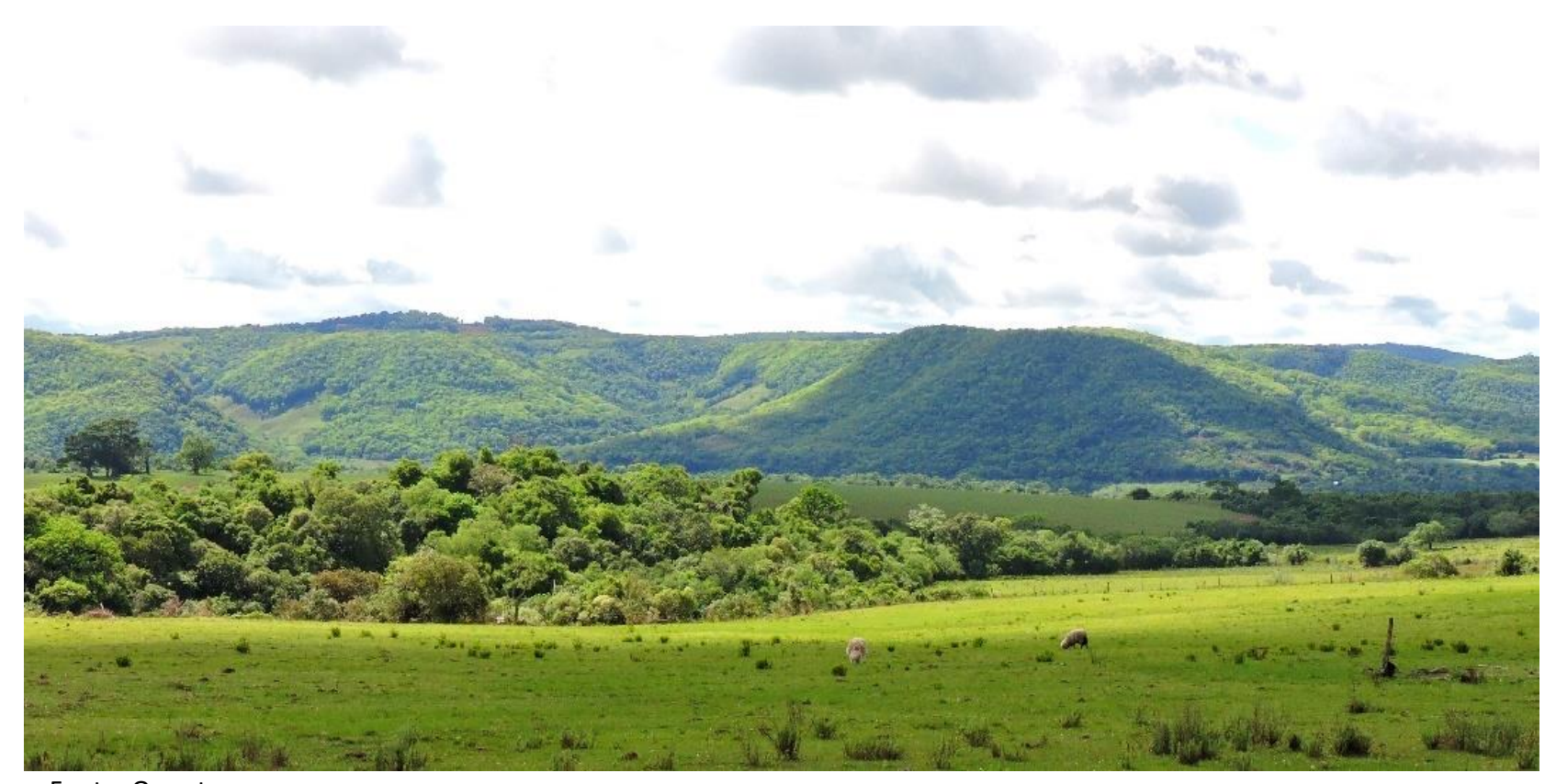

Fonte: Os autores

\section{Unidade do Chapadão}

Essa unidade forma um relevo suave entre escarpas representado por colinas suaves sobre um substrato de arenitos intercalados com vulcânicas. Ocupa 3,67\% da área total, localizada na forma de uma faixa central no município. Na subunidade A os solos são bem desenvolvidos formando Latossolos e Argissolos com textura arenosa. Na subunidade B apresenta porções do substrato, mais resistentes a alteração superficial e, por isso, formam porções com solos mal desenvolvidos, identificados como Neossolos litólicos (Figura 5). 
Figura 5. Colina com solos pedrogosos e lavoura de fumo, na unidade Chapadão. 09/2017

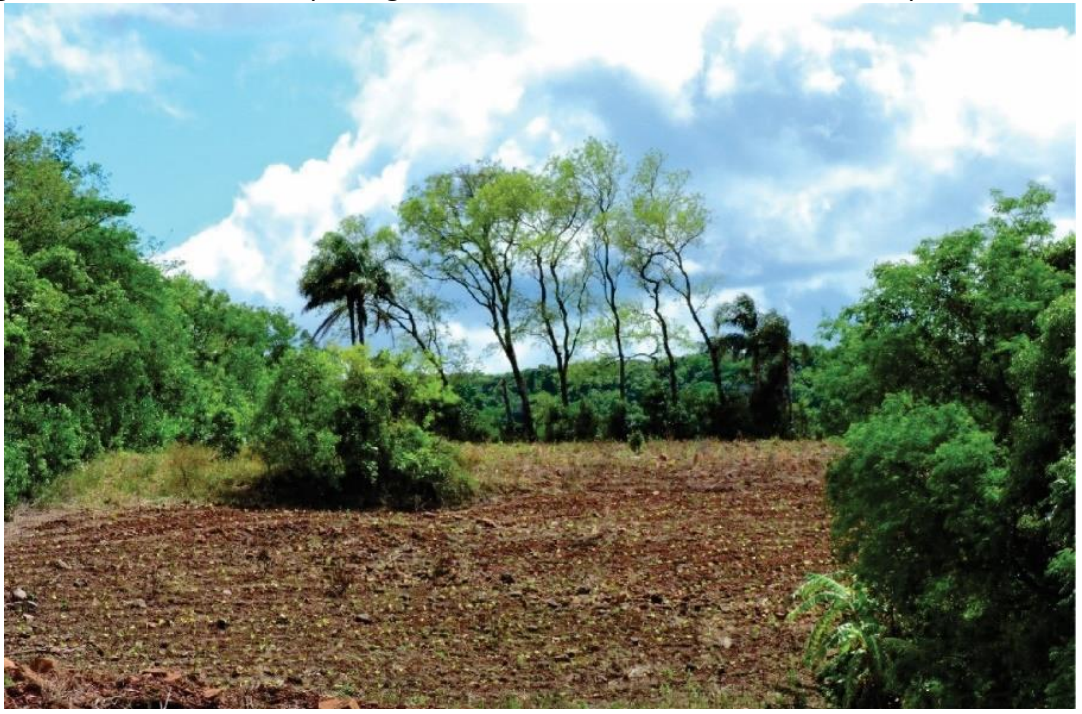

Fonte: Os autores

\section{Unidade dos Cerros}

Essa unidade representa o recuo do Planalto, por ação erosiva, ocorrem os morrotes isolados, conhecidos regionalmente como Cerros. Se caracterizam por elevações com amplitudes variando de $20 \mathrm{~m}$ a 100m e declividades superiores a 15\%. É a menor unidade fisiográfica, com apenas 1,51 \% da áera total do município, localizada de forma bastante dispersa pelo centro sul do município registrando o recuo do planalto. Na subunidade A o topo é plano formado por um substrato de arenito. Alguns mais significativos são: o Cerro da Carpintaria, Cerro dos Alazões, Cerro Alto Alegre (Figura 6), Cerro Potreiro Redondo e Cerro dos Negros nas porções Sul e Sudeste do município. Na subunidade B o topo é sustentado por rochas vulcânicas. Formam algumas elevações importantes como o Cerro Pelado (Figura 7), na entrada da cidade e os Cerros da Vigia e do Pereira ao Norte do município.

Figura 6. Morrote isolado de arenito (Cerro Alto Alegre) com depósitos de blocos e matacões na meia encosta e vegetação nativa preservada. 09/2017

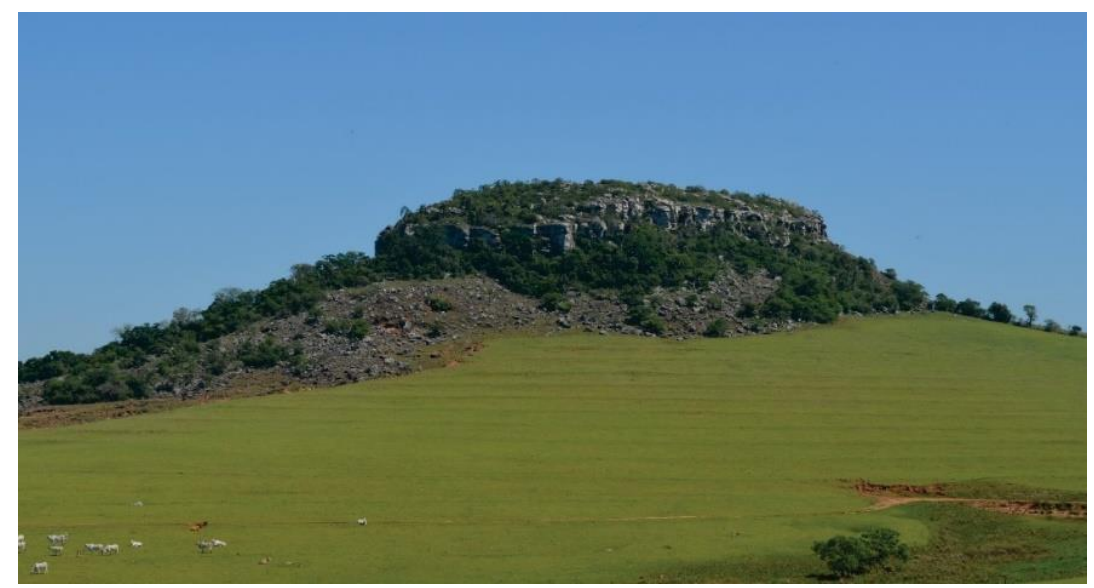

Fonte: Os autores 
Figura 7. Morrote com topo de vulcânica na entrada da cidade. 03/2016

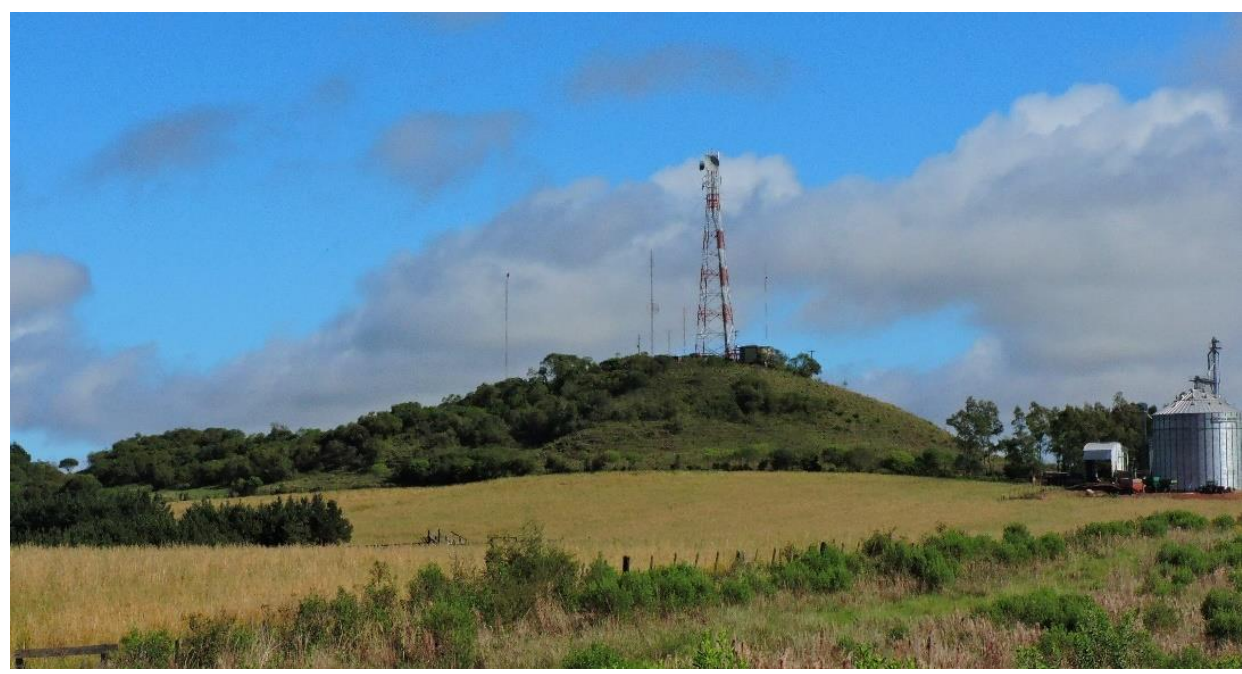

Fonte: Os autores

\section{Unidade dos Vales Fluviais}

No fundo dos vales, próximas as principais drenagens (rios Ibicuí e Jaguari), ocorrem as formas de rampas (Figura 8). As declividades são inferiores a 5\% e são marcadas por elementos flat, onde predominam processos de deposição e nos períodos de fortes chuvas são suscetíveis a sofrerem inundações. Esta unidade ocupa 10,32 \% da área total do município localizada principalmente na porção sul do município.

Figura 8. Planícies aluviais do rio Ibicuí. 09/2017

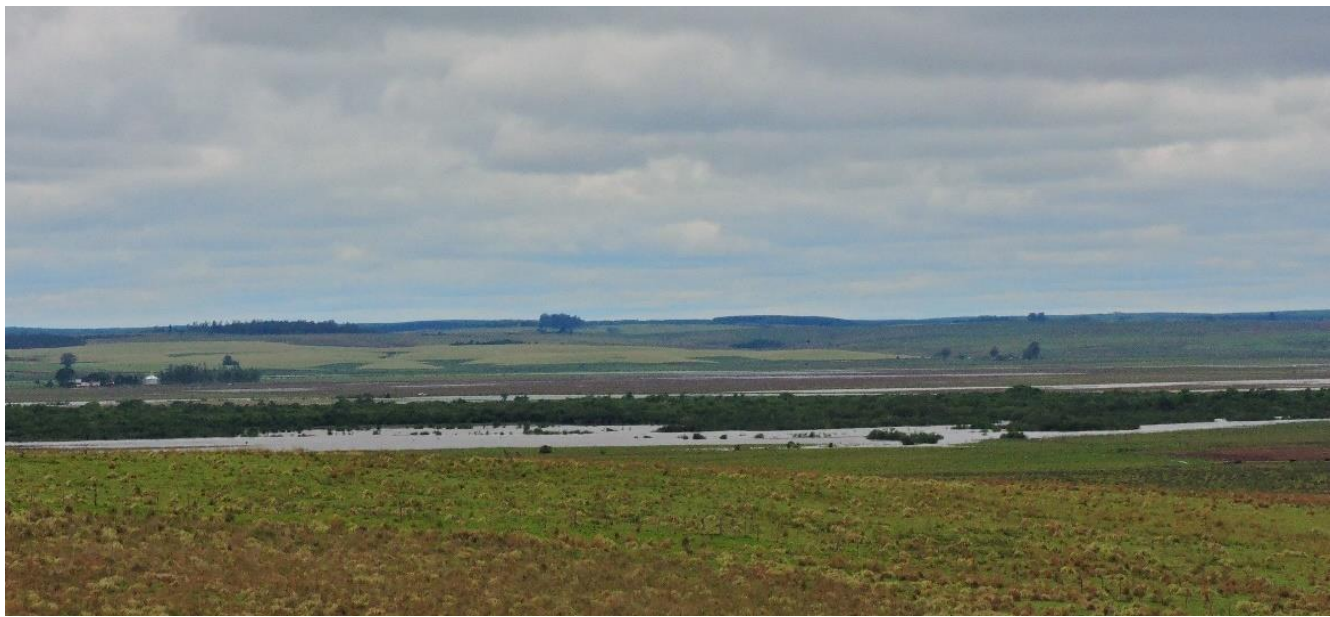

Fonte: Os autores

\section{Unidade Santa Rosa}

Unidade que marca as áreas de nascentes da bacia do rio Itu, formando relevo de colinas marcados por elementos de slope, com substrato de vulcânica e solos mal desenvolvidos (Figura 9), mas por vezes, com 
concentração de matéria orgânica no horizonte A, gerando Neossolos Litólicos Chernossólicos. Esta unidade ocupa 6,95 \% da área total, localizando-se em três áreas no norte e noroeste do município.

Figura 9. Colinas em áreas de altitude nas nascentes do rio Itu. 09/2017

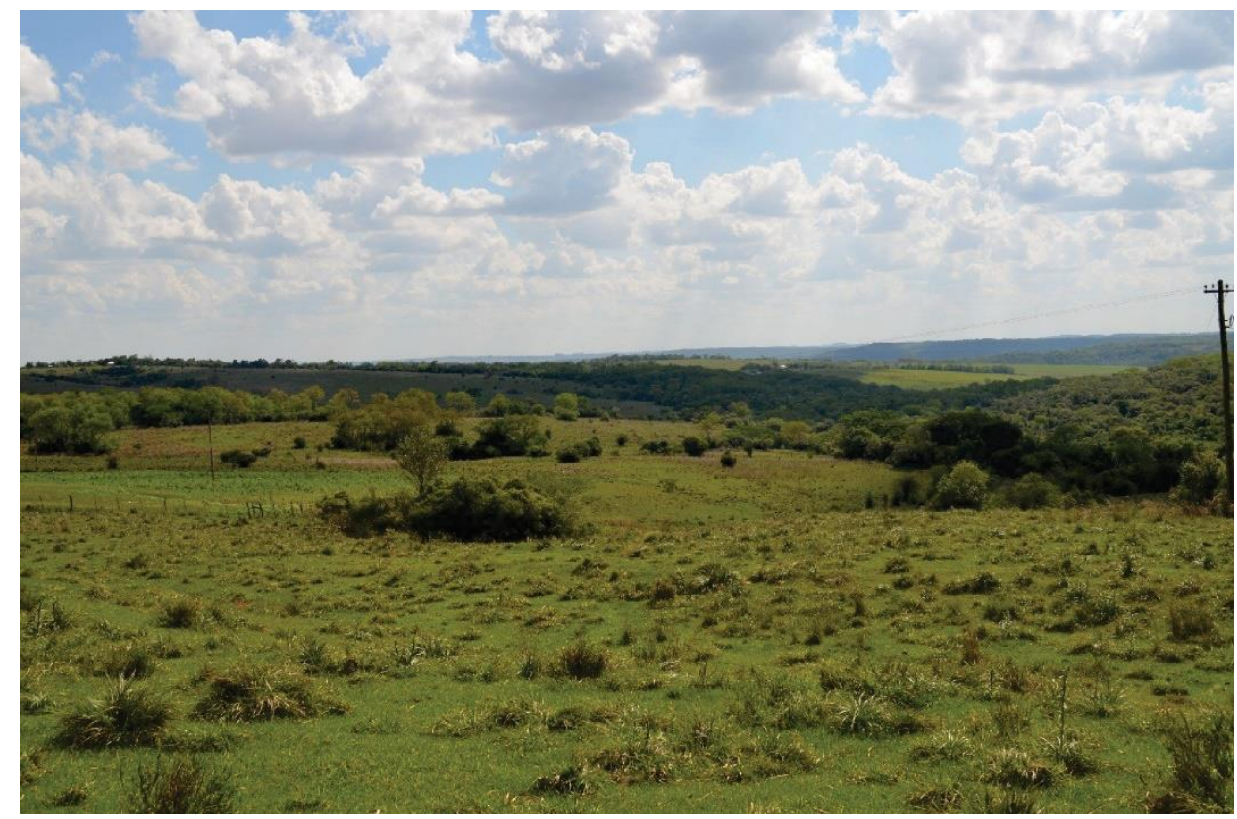

Fonte: Os autores

\section{Unidade São Francisco de Assis}

Essa unidade ocupa a maior área no município com $50,23 \%$ da área toal e, formada por um relevo suave constituido por colinas, onde os elementos predominantes são flat, slope, footslope e shoulder. O substrato é de rochas sedimentares areníticas. Na subunidade A ocorrem solos arenosos rasos a profundos, classificados como Latossolos arenosos. A subunidade B se localiza a SE do município com canais de drenagem mais abertos associado a um substrato de arenitos finos, micáceos onde os solos com espessura de $60 \mathrm{~cm}$ a $1 \mathrm{~m}$ desenvolvem horizonte textural, sendo classificados como Argissolos (Figura 10).

Em porções da unidade São Francisco de Assis, o teor de argila dos solos é muito baixo formando neossolos quartzarênicos e campos de areia, definidos como subunidade C (Figura 11). Os processos erosivos que originaram os conhecidos campos de areia ou areais de São Francisco de Assis são condicionados, principalmente, pela baixa coesão e cimentação de sedimentos e rochas areníticas. De modo geral, os areais encontrados no município abrangem uma área de cerca de $86,74 \mathrm{~km}^{2}$ se apresentando de diferentes formas e dimensões e, quando não expostos, se encontram cobertos predominantemente por vegetação rasteira (nativa ou plantada) típica de campo e vegetação arbórea representada pelos florestamentos (silvicultura). Os areais expostos se caracterizam por extensas áreas com processos erosivos e exposição de sedimentos arenosos retrabalhados pelo vento. Ainda, na unidade São Francisco de Assis, foi definida uma subunidade D 
onde a ocorrência de arenito mais resistentes, associados a derrames vulcânicos forma solos rasos, Neossolos Litólicos com afloramentos de rocha arenítica.

Figura 10. Colinas com Argissolos e lavoura de trigo na Unidade São Francisco de Assis (Subunidade B)

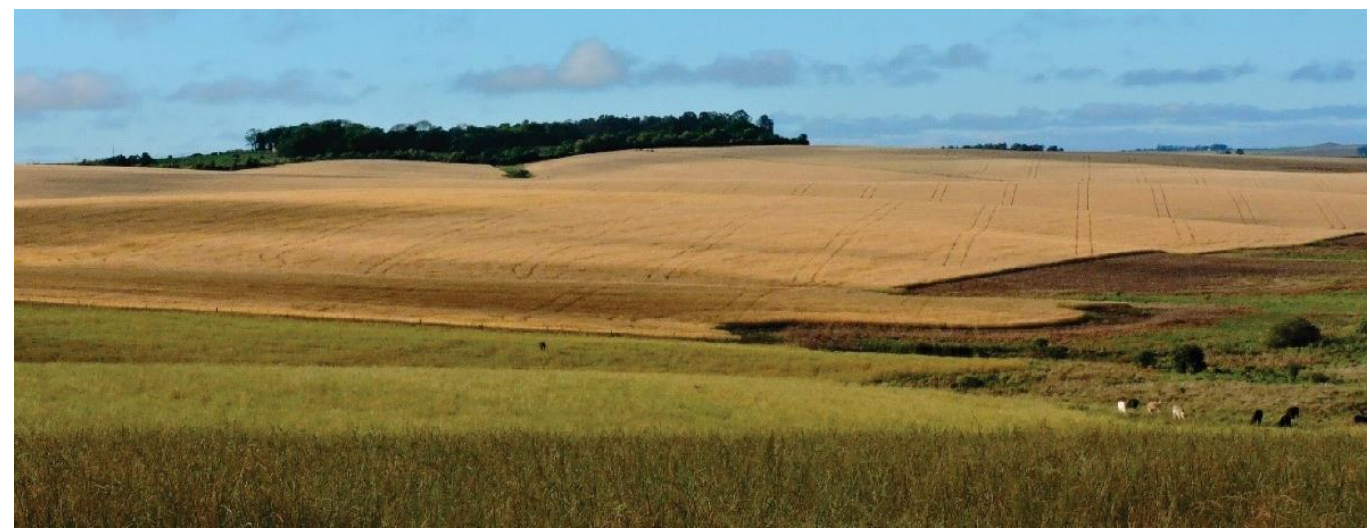

Fonte: Os autores

Figura 11. Colinas com neossolos quartzarênicos e campos de areia da Unidade São Francisco de Assis (Subunidade C)

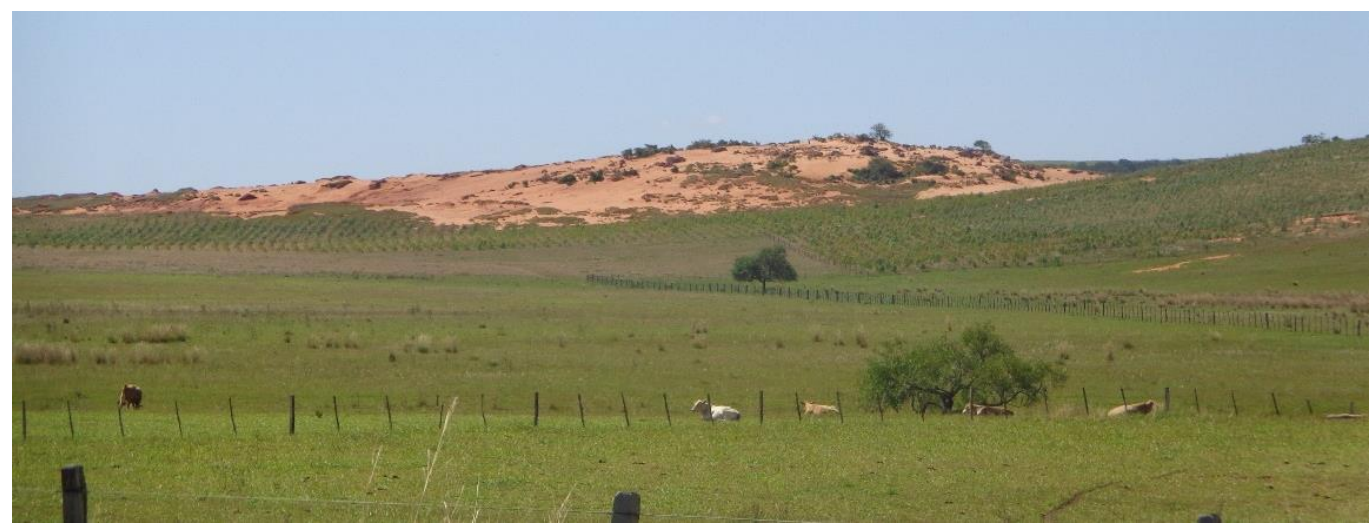

Fonte: Os autores

\section{Unidade Serra dos Canários}

Unidade localizada nas maiores altitudes, formando áreas de nascentes, com substrato de rochas vulcânicas em relevo de colinas suaves onde predomina os elementos flat e footslope (Figura 12). Esta unidade ocupa $5,77 \%$ da área total, localizada na porção nordeste do município. Na subunidade $A$ as áreas de nascentes são, principalmente dos afluentes do rio Jaguari, como os arroios Jaguari-mirim e Inhandiju. Nessa subunidade os solos não são espessos mas predominam solos bem desenvolvidos como Argissolos. Na subunidade B o predomínio é de solos rasos e mal desenvolvido, como Neossolos litólicos. As nascentes desta sub-unidade drenam diretamente para o rio Ibicuí, como os arroios Taquari e Caraí-Passos. 
Figura 12. Relevo de colinas que formam as áreas com altitudes no município, consituindo a Serra dos Canários

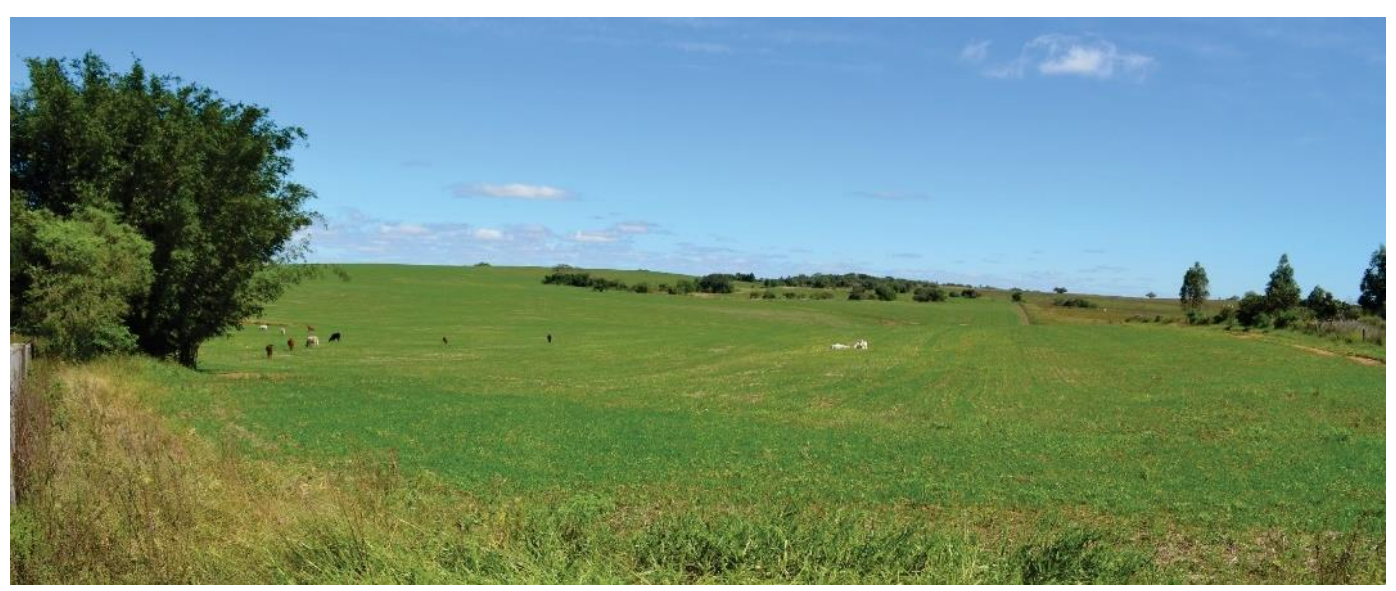

Fonte: Os autores

\section{Unidade Vila Kramer}

O relevo nessa unidade é de colinas onde elementos de slope, ridge e valley largos são os mais importantes. O substrato é de rochas vulcânicas com alguma intercalação de arenitos intertrápicos, formando solos, predominantemente bem desenvolvidos como Nitossolos vermelhos com presença de argila devido a alteração das porções de topo com material vítreo dos derrames. Esta unidade ocupa $6,84 \%$ da área total e localiza-se no centro norte e noroeste do município.

\section{CONSIDERAÇÕES FINAIS}

O município de São Francisco de Assis tem suas terras drenadas pela Bacia Hidrográfica do Ibicuí. O relevo é, predominantemente, ondulado com declividades entre 5 a 15\% e amplitude altimétrica de 380 metros. As rochas que afloram no município estão associadas a uma sequência vulcano-sedimentar, depositados na Bacia do Paraná. Os solos apresentam uma grande variabilidade em função de fatores como o material de origem e relevo, interferindo em características como cor, textura e profundidade, entre outras.

A análise e o cruzamento das informações de solo, unidades morfolitológicas e elementos de relevo, combinados com Sistemas de Informações Geográficas e árvores de decisão permitiu definir oito unidades fisiográficas e seis subunidades.

Foram definidas oito unidades fisiográficas: Unidade Beluno, do Chapadão, dos Cerros, dos Vales Flúviais, Santa Rosa, São Francisco de Assis, Serra dos Canários e Vila Kramer. A unidade Beluno representa a porção mais movimentada do rerevo com vertentes curtas e declividades acentuadas, sendo dividada em duas sub-unidades relacionadas aos tipos de solo e rocha destas unidades. 
A unidade do Chapadão apresenta relevo de colinas suave entre as escarpas com substrato de arenitos intercalados com vulcânicas. Se divide em duas sub-unidades em função dos tipos de solos presentes. A unidade dos Cerros representa os morrotes isolados, conhecidos regionalmente como Cerros e se divide em duas sub-unidades em função da litologia da área. A Unidade dos vales fluviais representa as áreas próximas as principais drenagens com áreas planas localizada principalmente na porção sul do município.

A unidade Santa Rosa representa as áreas de nascentes da bacia do rio Itu, formando relevo de colinas com solos mal desenvolvidos. A unidade São Francisco de Assis representa um relevo suave constituido por colinas de arenito, onde os elementos predominantes são flat, slope, footslope e shoulder. Esta unidade se divide em quatro sub-unidades relacionadas ao tipo de solo e substrato geológico que apreseta variações de texturas, condicionando porções de relevo com processos erosivos, ocorrência de areias e porções de arenitos mais resistentes.

A unidade Serra dos Canários representa as áreas mail altas do município, também associada às áreas de nascentes dos afluentes do rio Jaguari, como os arroios Jaguari-mirim e Inhandiju e do Ibicuí como os arroios Taquari e Caraí-Passos. Esta unidade se divide em duas sub-unidades em função da espessura e desenvolvimento dos solos. A unidade Vila Kramer representa áreas de colinas de rochas vulcânicas com alguma intercalação de arenitos intertrápicos onde elementos de slope, ridge e valley largos são os mais importantes, com solos bem desenvolvidos localizando-se no centro norte e noroeste do município.

As formas de relevo, as litologias e os solos constituem o substrato físico sobre o qual se desenvolvem as atividades humanas e dessa forma, trabalhos de zoneamentos que determinam unidades homogêneas são fundamentais para entendimento dos processos geomorfológicos e como as ações humanas podem interferir no ambiente. Dessa forma, permite analisar a relação entre processos superficias e os condicionantes ambientais, auxiliando o desenvolvimento de propostas de planejamento e uso do solos.

\section{REFERÊNCIAS}

ANTONELI, V; THOMAZ, E. L. Caracterização do meio físico da bacia do Arroio Boa Vista, Guamiranga/PR. Revista Caminhos da Geografia, Uberlândia, v.8, n.21, p46-58, 2007.

EMPRESA BRASILEIRA DE PESQUISA AGROPECUÁRIA - EMBRAPA. Centro Nacional de Pesquisa de Solos. Sistema brasileiro de classificação de solos. Brasília, SPI/ CNPS, 1999. 412p

INSTITUTO BRASILEIRO DE GEOGRAFIA E ESTATÍSTICA (IBGE). Projeto RADAMBRASIL. Levantamento de recursos naturais (Folha SH.22 Porto Alegre e parte das Folhas SH.21 Uruguaiana e SI.22 Lagoa Mirim). Instituto Brasileiro de Geografia e Estatística, Rio de Janeiro, CD-ROM. 1986.

INSTITUTO BRASILEIRO DE GEOGRAFIA E ESTATÍSTICA (IBGE). Malhas Digitais. Municípios 2010, Rio de Janeiro,2010. Disponível em <http://downloads.ibge.gov.br/downloads_geociencias.htm> Acesso junho de 2015.

JASIEWICZ, J., \& STEPINSKI, T. F. Geomorphons-a pattern recognition approach to classification and mapping of landforms.

Geomorphology. 2013, 182. https://doi.org/10.1016/j.geomorph.2012.11.005 
LAVINA, E. L. The Passa Dois Group. In: ANAIS DO INTERNATIONAL GONDWANA SYMPOSIUM, 7, 1988. São Paulo. São Paulo: Instituto de Geociências, 1988. p. 24-30. 1988.

LOLLO, J. A. O uso da técnica de avaliação do terreno no processo de elaboração do mapeamento geotécnico: sistematização e aplicação na quadrilha de Campinas. 1996. Tese (Doutorado) - Universidade de São Paulo, São Carlos.

MENEZES, D. J.; TRENTIN R.; ROBAINA, L. E. S.; SCCOTI, A. A. V.. Compartimentação geomorfológica do município de São Pedro do Sul/RS. Boletim Gaúcho de Geografia, 40: 268-279, maio, 2013.

ROBAINA, L. E. S.; TRENTIN, R.; BAZZAN, T.; RECKZIEGEL, E. W.; VERDUM, R.; DE NARDIN, D. Compartimentação geomorfológica da bacia hidrográfica do Ibicuí, Rio Grande do Sul, Brasil: Proposta de classificação. Revista Brasileira de Geomorfologia, v. 11, n. 2, p. 11-23, 2010.

ROBAINA, L. E. S.; TRENTIN, R.; LAURENT, F.; SCCOTI, A. A. V. Zoneamento morfolitológico da bacia hidrográfica do rio Ibicuí e sua relação com processos superficiais e o uso do solo. Revista Brasileira de Geomorfologia, São Paulo, v.16, n.1, (Jan-Mar) p.63-77, 2015.

ROBAINA, L. E. S.; TRENTIN, R.; LAURENT, F. Compartimentação do estado do Rio Grande do Sul, Brasil, através do uso de geomorphons obtidos em classificação topográfica automatizada. Revista Brasileira de Geomorfologia, São Paulo, v.17, n.2, (Abr-Jun) p.287-298, 2016.

ROISENBERG, A. e VIERO, A. P. O Vulcanismo Mesozóico da Bacia do Paraná no Rio Grande do Sul. In: HOLZ, M. e DE ROS, L.V. Geologia do Rio Grande do Sul. Porto Alegre: CIGO/UFRGS, 2002. p.355-374.

SENA-SOUZA; J; NEVES, G.; VASCONCELOS, V.; MARTINS, E.; JUNIOR, A. Mapeamento das Formas de Terreno por meio de Assinatura Geomorfométrica como Subsídio para a Descrição da Paisagem da Bacia Hidrográfica do Alto Rio Preto. Anais XVII Simpósio Brasileiro de Sensoriamento Remoto - SBSR, João Pessoa-PB, Brasil,25 a 29 de abril de 2015, INPE, pag. 1617-1624.

STRECK, E. V. et al. Solos do Rio Grande do Sul. 2. ed. Porto Alegre: Emater/RS, 2008.

SUERTEGARAY, D. M. A. O Rio Grande do Sul descobre seus “desertos”. Ciência \& Ambiente, v. 1, n. 1, p. 34-52, 1995.

SUERTEGARAY, D. M. A.; GUASSELI, L. A.; VERDUM, R. Atlas da arenização: Sudoeste do Rio Grande do Sul. Porto Alegre: Secretaria da Coordenação e Planejamento do Rio Grande do Sul, 2001.

TERAMOTO, E.R.; LEPSCH, I.F. e VIDAL-TORRADO, P. Relações solo, superfície geomórfica e substrato geológico na microbacia do ribeirão Marins (Piracicaba-SP). Scientia Agricola, 58:361-371, 2001.

TRENTIN, R.; SANTOS, L. J. C.; ROBAINA, L. E. S. Compartimentação geomorfológica da bacia hidrográfica do rio Itu - Oeste do Rio Grande do Sul - Brasil. Sociedade \& Natureza, v. 24, n. 1, p. 127-142, 2012.

TRENTIN, R.; ROBAINA, L. E. S.; SCCOTI, A. A. V. Mapeamento geomorfológico do município de Manoel Viana - oeste do Rio Grande do Sul - Brasil. São Paulo, Geociências, v. 32, n.2, p. 333-345, 2013.

TRENTIN, R.; ROBAINA, L. E. S.; SILVEIRA, C. T. Compartimentação geomorfométrica da bacia hidrográfica do rio Itu/RS. Revista Brasileira de Geomorfologia, São Paulo, v.16, n.2, (Abr-Jun) p.219-237, 2015.

UNITED STATES GEOLOGICAL SURVEY (USGS). USGS Global Visualization Viewer. Disponível em : << https://Ipdaac.usgs.gov/data_access/glovis >>. Acesso em fevereiro de 2015.

VERDUM, R. Approche Géographique des "Deserts” Dans les Communes de São Francisco de Assis et Manuel Viana - Etat du Rio Grande do Sul, Brésil. Tese de Doutorado. França: Université de Toulouse Le Mirail - UFR de Géographie, 1997. 211p.

VERDUM, R., et al. Rio Grande do Sul: paisagens e territórios em transformação. Porto Alegre: Editora da UFRGS, 2004.319 p.

WILDNER, W; RAMGRAG, G. E.; LOPES R. C.; IGLESIAS, C. M. F. Mapa Geológico do Estado do Rio Grande do Sul. Escala 1:750000. CPRM, Serviço Geológico do Brasil. Porto Alegre, RS. 2006. 